\title{
THE POSTPARTUM MENSTRUATION OF CYNOMOLGUS MONKEYS KEPT UNDER THE LABORATORY CONDITIONS
}

Since 1962, we have done some surveys on the reproductive phenomena of cynomolgus monkeys (Macaca irus) under the laboratory conditions. The purpose of this brief note is to provide data of the postpartum amenorrheal period and of the recurrence of regular menstrual cycles in the cynomolgus monkeys which were delivered in our monkey facility.

\section{Materials and Methods.}

Postpartum menstruation was observed in 20 apparently healthy cynomolgus monkeys imported from Southeast Asia. Thirty-five full-term-deliveries occurred in these 20 females, that is, each female was delivered one to five times. Eleven of the 35 deliveries were cases which had become pregnant in the natural habitat (in-nature bred monkeys). The remaining 24 deliveries were cases which became pregnant by the one-to-one mating system in our monkey facility (laboratory bred monkeys) (Fujiwara et al., 1969). Two of the 20 monkeys were used for another experiment after the observation of the 1st postpartum menstruation, and the remaining 18 females were retained for the observation of the 2nd postpartum menstruation. Moreover, some of the 18 females were mated arbitrarily.

The details of the mating system employed for cynomolgus monkeys in our breeding colony have been described elsewhere (Fujiwara et al., 1969).

On the basis of the data presented in the previous reports (Spiegel, 1950, Fujiwara et al., 1969), we usually regard delivery occurring before the 150th day of gestation period as the premature one.

Methods of checking the menstruation and of the care and management of animals were described previously (Fujiwara, et al., 1967).

In this note, the postpartum amenorrheal period is defined as the duration from the day after the delivery to the day before the 1st postpartum menstruation. The first postpartum menstrual cycle means the duration from the 1st day of the 1st postpartum menstruation to the day before the 2nd one.

Baby monkeys were weaned between days 91 and 120 after the birth.

Results.

Postpartum amenorrheal period: The length of postpartum amenorrheal period which was observed in the 35 deliveries ranged from 29 to 315 days (Fig. 1). A peak of frequency was found between 121 and 150 days postpartum. Postpartum amenorrheal periods observed in the in-nature bred monkeys were generally longer than those in the laboratory bred monkeys $(\mathrm{P}<0.05)$. The length of the 35 cases averaged 151.1 days with a standard deviation of \pm 79.3 days. In the eleven innature bred females, an average \pm standard deviation was $209.2 \pm 80.4$ days, and that of the 24 laboratory bred females was $124.5 \pm 49.9$ days. Significant difference 


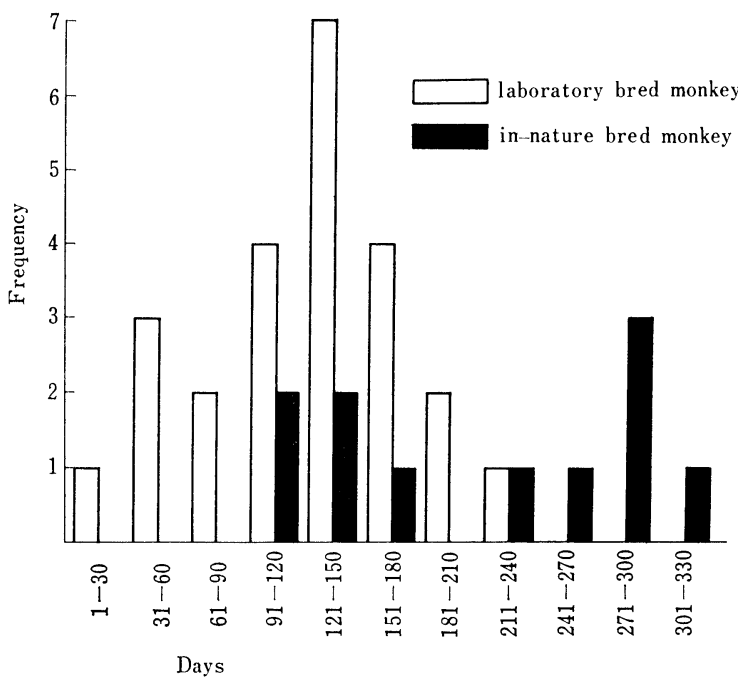

Fig. 1. Frequency distribution of the postpartum amenorrheal periods in 35 deliveries.

Table 1. Changes of length of the postpartum menstrual cycles

\begin{tabular}{|c|c|c|c|c|c|c|}
\hline & $\begin{array}{l}\text { 1st } \\
\text { post- } \\
\text { partum } \\
\text { cycle }\end{array}$ & $\begin{array}{l}\text { 2nd } \\
\text { post- } \\
\text { partum } \\
\text { cycle }\end{array}$ & $\begin{array}{l}\text { 3rd } \\
\text { post- } \\
\text { partum } \\
\text { cycle }\end{array}$ & $\begin{array}{l}\text { 4th } \\
\text { post- } \\
\text { partum } \\
\text { cycle }\end{array}$ & $\begin{array}{l}5 \text { th } \\
\text { post- } \\
\text { partum } \\
\text { cycle }\end{array}$ & $\begin{array}{l}\text { 6th } \\
\text { post- } \\
\text { partum } \\
\text { cycle }\end{array}$ \\
\hline No. of cycles observed & 29 & 19 & 18 & 12 & 12 & 10 \\
\hline Range (day) & $17-88$ & $22-54$ & $23-94$ & $23-33$ & $20-33$ & $25-34$ \\
\hline Average length (day) & 38.7 & 34.3 & 32.0 & 28.3 & 27.9 & 28.3 \\
\hline Standard deviation (day) & \pm 16.6 & \pm 8.4 & \pm 15.4 & \pm 3.0 & \pm 3.4 & \pm 2.5 \\
\hline $\begin{array}{l}\text { Rate of occurrence of } \\
\text { abnormal cycle* }(\%)\end{array}$ & 34.5 & 26.3 & 11.1 & 0 & 0 & 0 \\
\hline $\begin{array}{l}\text { Confidence limits** on } \\
\text { the rate of occurrence } \\
\text { of abnormal cycle }(\%)\end{array}$ & $20.1-51.6$ & $11.0-47.6$ & $2.1-31.0$ & $0-22.1$ & $0-22.1$ & $0-25.9$ \\
\hline
\end{tabular}

* The cycle outside the range of $28.5 \pm 9.9$ days (Fujiwara et al., 1967).

$* * \mathrm{P}=0.05$.

was noted between the two average values at the $5 \%$ level.

The length of the period of 5 non-lactating females which produced still-birth was not always shorter than that of the lactating females in both the laboratory bred and the in-nature bred groups. In the laboratory bred group, 9 of 20 lactating females $(45.0 \%)$ showed the 1st postpartum menstruation during the lactation period of 3 months. On the other hand, in none of 10 lactating females of the in-nature bred group did the 1st postpartum menstruation occur during the lactation period.

Postpartum menstrual cycle: In 18 females having been delivered of 29 times, a total of 100 postpartum menstrual cycles of both the laboratory bred and the 
in-nature bred groups were observed. Table 1 summarizes the statistically analysed results from these 100 cycles. The average value and the standard deviation of the first postpartum cycles were largest, compared with the 2nd-6th cycles observed. The values obtained from 34 cycles between the 4 th and 6 th postpartum cycles were relatively stable. The highest percentage frequency of the occurrence of abnormal menstrual cycle (Fujiwara et al., 1967) was found in the 1st cycle and the frequency decreased gradually in the subsequent cycles. As can be easily understood from the fluctuation of the confidence limits, the percentage occurrence of abnormal cycles decreased gradually and would not exceed about $25 \%$ after the 4 th postpartum cycle.

Frequency distribution of all the 100 cycles is shown in Fig. 2. Though the longest cycle (94 days) was found at the 3 rd postpartum cycle, it was clearly demonstrated that the regularity of cycle in each female recovered in due course of the postpartum time.
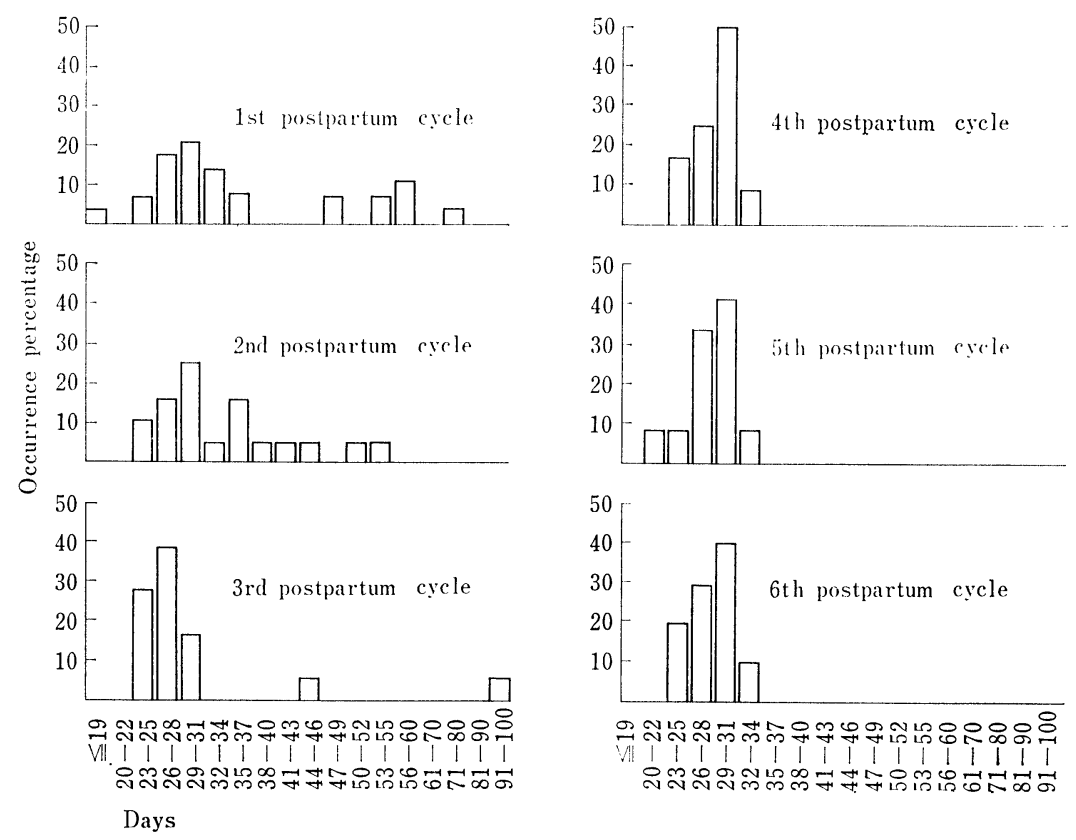

Fig. 2. The rate of occurrence frequency of the postpartum menstrual cycles.

The length of the 1st postpartum cycle was inversely related to that of the postpartum amenorrheal period in the laboratory bred animals $(\mathrm{r}=-0.61, \mathrm{P}<0.05)$. In other words, the longer the postpartum amenorrheal period, the shorter the 1st postpartum menstrual cycle.

\section{Comment.}

In 20 cynomolgus monkeys, the postpartum amenorrheal periods and the succeeding menstrual cycles were analysed. Results obtained suggest the following 
two points. First, judging from the recurrence of menstruation (Fig. 2), the postpartum recovery of reproductive function of cynomolgus monkeys in our laboratory are generally completed by the 4 th postpartum cycle, that is, about 230 days after delivery on the average. At present, however, we have mentioned only a few factors (e.g. origin of pregnant females and presence or absence of lactation) relating to the recurrence of postpartum menstruation, and other factors (e. g. gestation period, weight of newborn, and frequency of delivery) were not considered. Further surveys should be carried out to clarify the effect of the latter factors on the recurrence of the postpartum menstruation. Second, the average length of the postpartum amenorrheal period is longer in the in-nature bred monkeys than in the laboratory bred monkeys. The prolongation of the recurrence of the postpartum menstruation in the in-nature bred monkeys might probably be evoked by some stressful situations during the period from conception to delivery (e.g. rapid transfer from their natural habitat to the artificial feeding environment).

From the data of Spiegel (1950) concerning the postpartum menstruation of cynomolgus monkeys, it can be estimated that the postpartum amenorrheal period averages 6.2 months, ranging from 2 to 13 months. These values are almost equal to those of the in-nature bred monkeys in our laboratory.

In the laboratory bred monkeys, $45 \%$ of all the nursing females showed recurrence of menstruation within the lactation period. Hence, contrary to the description of Zuckerman (1931), we should like to maintain that the lactation period of cynomolgus monkeys kept under laboratory conditions is not always equivalent to the amenorrheal period.

Generally, it may be said that the monkey which completes her postpartum recovery relatively soon after delivery is suitable for breeding animals. Thus, the present data would provide a reference for choosing a good female monkey for breeding.

Strictly speaking, in monkeys, not only the postpartum recurrence of menstruation but also the postpartum recovery of the genital organs and of other factors (e. g. hematological values) may be regarded as criteria for the recorery of the fertility after delivery. This problem remains a subject for further studies.

\section{REFERENCES}

Fujiwara, T., Uchino, I., Honjo, S., Imaizumi, K. And Imamichi, T. (1967): Normal range of the menstrual cycle of cynomolgus monkeys under laboratory conditions. Japan. J. Med. Sci. Biol., 20, 505-507.

Fujiwara, T., Honjo, S. ANd Imaizumi, K. (1969): Practice in the breeding of cynomolgus monkeys (Macaca irus) under laboratory conditions. Experimental Animals 18, 29-40.

SPIEGEL, A. (1950): Weitere Beobachtungen und Untersuchungen über die Fortpflanzung bei Javamakaken (Macaca irus mordax Th. und Wr. (Cynomolgus L.)). Arch. Gynäk. $177,590-629$.

ZUCKERMAN, S. (1931): The menstrual cycle of primates. Part IV. Observations on the lactation period. Proc. zool. Soc. Lond. 1, 593-602. 
Department of Veterinary Science,

TOORU FUJIWARA

National Institute of Health,

SHIGEO HONJO

Shinagawa-ku, Tokyo 141, Japan

KIYOSHI IMAIZUMI

Department of Physiology, Nippon Veterinary

TOMONORI IMAMICHI and Zootechnical College, Tokyo 180, Japan

Received: May 22nd, 1969

藤原徹・本左重男・今泉清（国立予防衛生研究所獣疫部）

今道友則（日本獣医畜産大学生理学教室） 